\title{
EXPERIMENTAL VALIDATION OF THE USE OF ENERGY TRANSFER RATIO (ETR) FOR DAMAGE DIAGNOSIS OF STEEL-CONCRETE COMPOSITE BEAMS
}

\author{
Tomasz Wróblewski, MaŁgorzata Jarosińska, MaŁgorzata Abramowicz \\ West Pomeranian University of Technology, Department of Theory of Structure, Szczecin, Poland \\ e-mail: wroblewski@zut.edu.pl, jarosinska@zut.edu.pl,mabramowicz@zut.edu.pl \\ STEFAN BercZyŃsKI \\ West Pomeranian University of Technology, Institute of Manufacturing Engineering, Szczecin, Poland \\ e-mail: Stefan.Berczynski@zut.edu.pl
}

\begin{abstract}
The paper presents changes of modal parameters such as natural frequencies, damping ratios and energy transfer ratios (ETR) following damage of the connection of a steel-concrete composite beam. Sensitivity analysis of the parameters is conducted both for numerical simulation and experimental results. The energy transfer ratio ETR is determined: i) for the whole beam - as a global parameter which can be used for damage detection, ii) for segments of the beam - as a local parameter which can be used for damage localisation.
\end{abstract}

Keywords: damage diagnosis, energy transfer ratio (ETR), steel-concrete composite beams

\section{Introduction}

Steel-concrete composite beams are often used in the bridge engineering as main carrying girders. Safety of bridge structures, both during constructional work and particularly during their use, is of major importance. Therefore, continuous monitoring of the structure condition is an increasingly common practice with a view to damage diagnosis in early stages for substantial reduction of the cost of necessary repairs. Monitoring systems are often based on non-destructive damage detection methods. They enable damage detection in places inaccessible during visual inspection, e.g. in shear connectors of steel-concrete composite bridges (Liu and de Roeck, 2009; Li et al., 2014a,b; Dilena and Morassi, 2004, 2009).

Non-destructive methods are often based on measurements of vibration of the structure. Vibrations that are excited by a changing load are recorded and modal characteristics of the structure are analysed. When damage appears, stiffness, damping and sometimes mass of the structure change, causing changes in frequency response functions. This is reflected in changes of modal parameters, including natural frequencies, mode shapes and damping parameters. Methods based on analysis of such changes can provide an effective tool to damage diagnosis. One of them, which deserves an in-depth analysis, is based on changes of the energy transfer ratio (ETR). Since the method is used for non-proportionally damped structures, it has gained little recognition as most studies assume analysed structures to be proportionally damped.

The energy transfer ratio was defined by Liang and Lee (1991). It defines the ratio of energy which is transferred between different mode shapes. Based on an experimental research conducted on a model of a composite bridge, the authors demonstrated that ETR was much more sensitive to damage than the natural frequency or damping ratio. Their study revealed that modal energy was transferred not only between mode shapes but also between their fragments. It means that ETR can be determined both globally, for the whole construction, and locally, for its segments, which can be used for damage localisation. Similar studies conducted on composite 
bridge models were also carried out by Kong et al. (1996), Liang et al. (1997), Wang and Zong (2002, 2003).

The present paper is a continuation of two earlier studies published by Wróblewski et al. (2011, 2013) which demonstrated a method of how ETR changes could be used for damage detection and localisation in steel-concrete composite beams. The results obtained in numerical analysis confirmed that ETR was more sensitive to changes in steel-concrete beam structure than the natural frequency or damping ratio. However, it should be pointed out that the studies were based on numerical damage simulation only. The present paper assesses changes of modal parameters both based on numerical simulation results and experimental data. ETR is discussed and tested as a damage detection tool, i.e. as a global parameter determined for the whole beam and as a local parameter determined for segments of the beam, which can be useful for damage localisation.

\section{Experimental research}

The analysed composite beam measures $3200 \mathrm{~mm}$ in length and consists of IPE 160 made of S235JRG2 steel, connected to a concrete slab made of C30/37 concrete. The connection between the concrete and steel is made using headed steel studs, $10 \mathrm{~mm}$ in diameter and $50 \mathrm{~mm}$ in height. The studs are placed in pairs every $150 \mathrm{~mm}$. The cross-section of the beam and stud distribution along the beam are shown in Fig. 1.

(a)

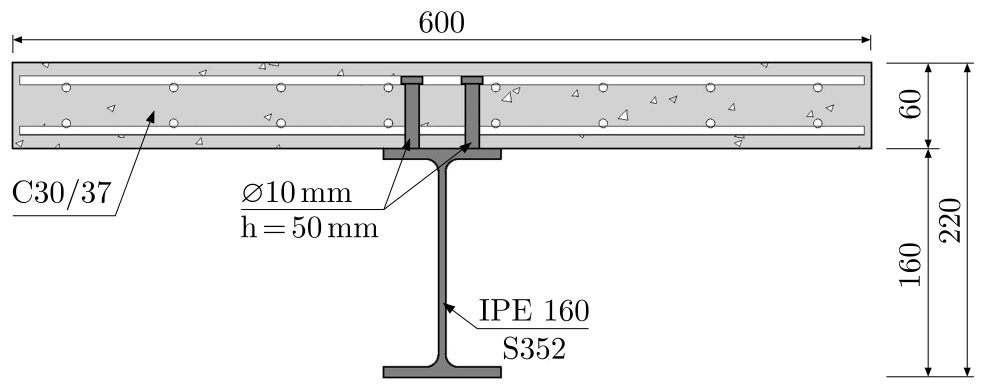

(b)

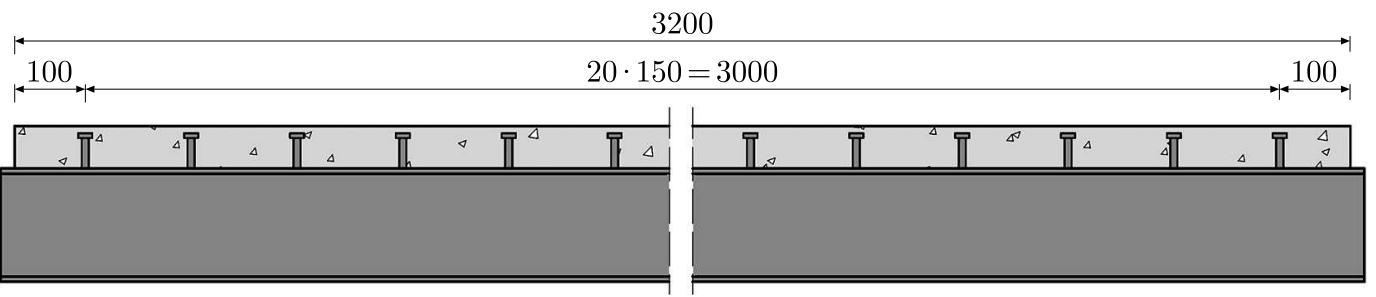

Fig. 1. Composite beam: (a) cross-section, (b) distribution of connectors

Experiments have been conducted for a free-free beam. They were carried out by suspending the tested beam on a steel frame by means of four elastic steel cables. The places where the cables were attached to the concrete slab overlapped with the nodes of the fundamental flexural mode shape of vibration of the beam.

An impulse test with a modal hammer was conducted to excite vibration of the structure. The system response was measured in three orthogonal directions using piezoelectric accelerometers. LMS SCADAS III, a multi-channel analyser, was used to measure the signal. It was connected to a workstation, fitted with LMS Test.Lab software.

A grid of 52 measurement points were defined on the beam. In these points, accelerations were measured. Two additional points, 53 and 54, were situated at one end of the beam. To excite flexural vibration of the beam, force impulse was applied at point 53 perpendicularly to 
the slab ( $-Y$ direction). To excite axial vibration of the beam, a force impulse was delivered at point 54 , on the slab edge ( $+X$ direction). A grid of measurement points and the directions of the force impulse are presented in Fig. 2.

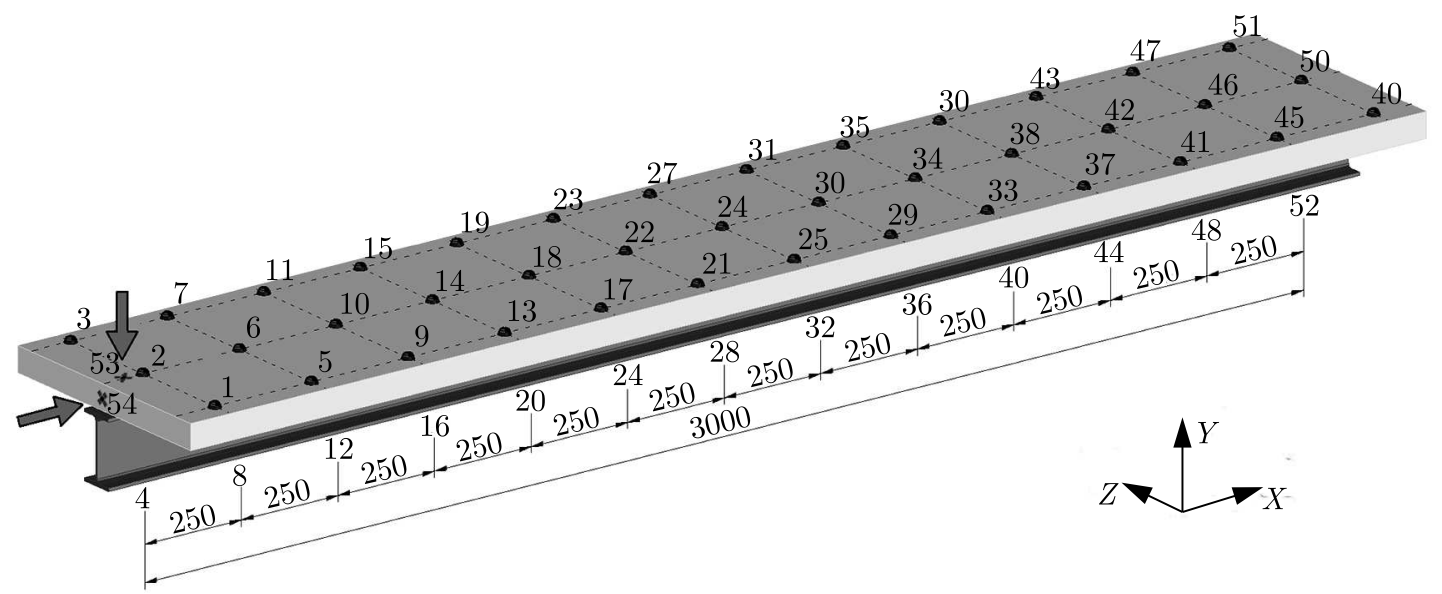

Fig. 2. Measurement point grid, points and directions of the force impulse

The Polymax algorithm, available in Test.Lab, was used to determine parameters of the modal beam model. The poles of the system were identified based on the analysis of a stabilisation diagram. Only the measurement points on the beam mid plane $(2,4,6,8, \ldots, 52)$ were used in the analysis. This approach substantially made it easier to find flexural vibration modes which were later analysed to detect and locate damage. It also enabled analysis of a two-dimensional beam model.

Natural frequencies $f_{i, \exp }$ obtained in experimental research and their corresponding modal damping ratios $\xi_{i, \exp }$ for the first five flexural mode shapes are presented in Table 1.

Table 1. Modal parameters obtained during experimental research

\begin{tabular}{|c||c|c|c|c|c|}
\hline$i \rightarrow$ & $1_{\text {flex }}$ & $2_{\text {flex }}$ & $3_{\text {flex }}$ & $4_{\text {flex }}$ & $5_{\text {flex }}$ \\
\hline \hline$f_{i, \exp }[\mathrm{Hz}]$ & 74.68 & 172.72 & 273.01 & 373.40 & 472.03 \\
\hline$\xi_{i, \exp }[\%]$ & 0.15 & 0.30 & 0.41 & 0.39 & 0.34 \\
\hline
\end{tabular}

In the successive stage of the experiment, connection damage was introduced into the beam. The damage was obtained by removing concrete around a pair of studs, which eliminated the interaction between steel and concrete (Fig. 3). Dilena and Morassi (2003) used the same approach to simulate damage.

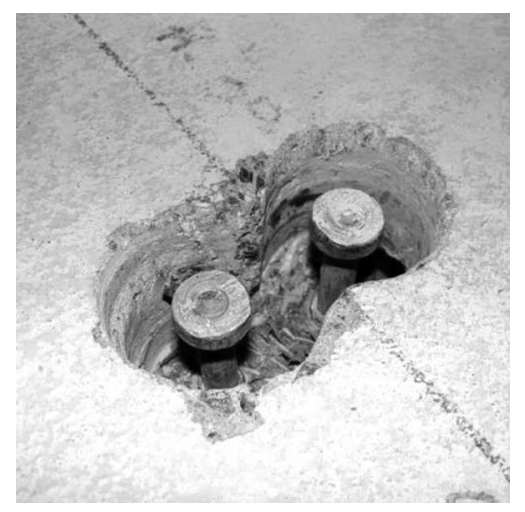

Fig. 3. Damage of the connection 
Two degrees of damage, denoted by UZ1 and UZ2, were introduced into the beam. In damage UZ1 concrete was removed around one pair of studs (Fig. 4a) while in damage UZ2 around two pairs of studs (Fig. 4b).

(a) 3200

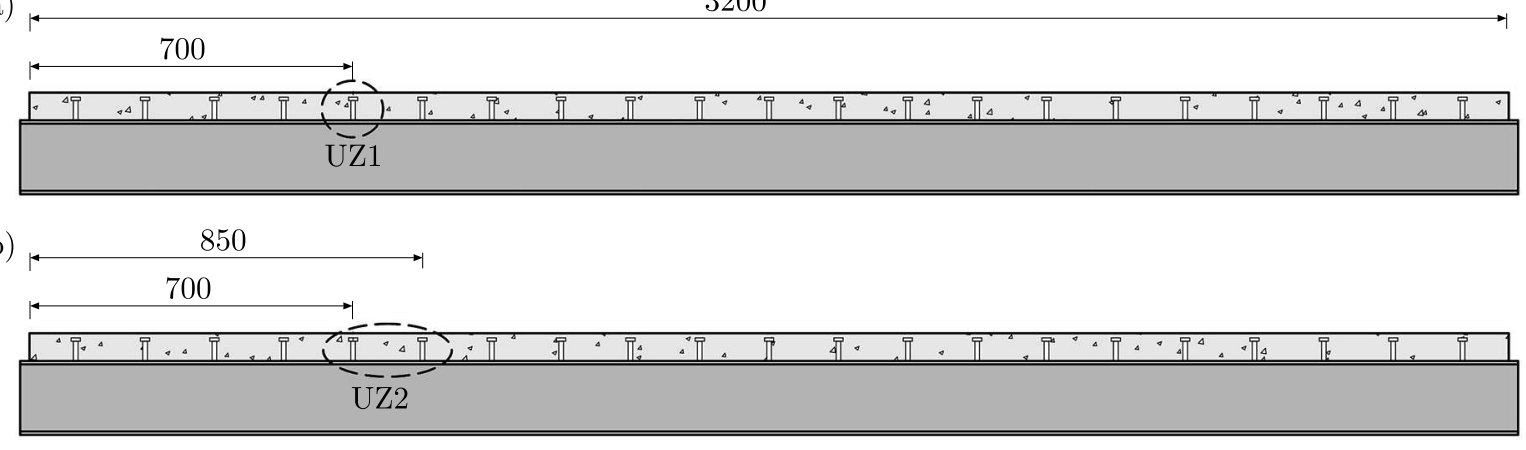

Fig. 4. Damage localisation: (a) damage UZ1, (b) damage UZ2

\section{Numerical analysis}

The numerical model of the beam has been created using the Rigid Finite Element method (Kruszewski et al., 1975, 1999; Wittbrodt et al., 2006). The central idea of the method is division of a real system into rigid bodies which are called rigid finite elements (RFE), which are then connected by means of spring-damping elements (SDE). For continuous parts of a structure, it is customary to start creating a model with segmentation of a beam into equal or nearly equal segments. This segmentation is also called a primary division, see Fig. 5a. A spring-damping element SDE is placed in the centre of gravity of every segment. This SDE is supposed to concentrate all spring and damping properties of a given segment. In Fig. 5b, SDE elements are shown as $\otimes$ symbols. In the $2 \mathrm{D}$ model, each SDE is made up of three (two translational and one rotational) independent spring-damping elements. The next step is to connect SDEs created in the primary division by means of RFE. This is the so-called secondary division, see Fig. 5b.

While creating the model, the steel and concrete parts of the beam are treated separately. Owing to this, the elasticity of the connection can be taken account of the simulations. The connection between adjacent rigid finite elements (RFE) modelling the concrete slab is performed in the classical way, i.e. using one SDE located in the axis of the slab. In the case of the steel beam, another approach is proposed. One SDE is substituted with three separate SDEs placed in the axes of the web and the flanges of the I-section. The SDEs modelling the connection are located in the place where in the real beam a pair of steel studs would be found. Figure 5 presents the composite beam model.

To develop a mathematical model of a composite beam, it is necessary to know parameters characterising the I-section, the concrete slab and the connection. Some parameters, e.g. Young's modulus of the steel, density of the materials, Poisson's ratios, cross-sectional areas, are determined on the basis of measurements and literature data. Other parameters necessary to define the model are determined in two-stage parametric identification.

The first identification stage has been focused on determining the missing stiffness parameters, i.e. Young's modulus of the reinforced concrete slab $E_{c}$ and stiffness of the connection $K_{v}$ in the vertical direction (perpendicular to the connection plane) and in the horizontal direction $K_{h}$ (parallel to the connection plane). The stiffness of the connection is influenced by spring properties of the steel studs, stiffness of concrete surrounding the studs and stiffness of the adjacent section of the steel-concrete interface. The first identification criterion is the best fit of the first five frequencies of flexural vibrations determined numerically to those found experimentally. 

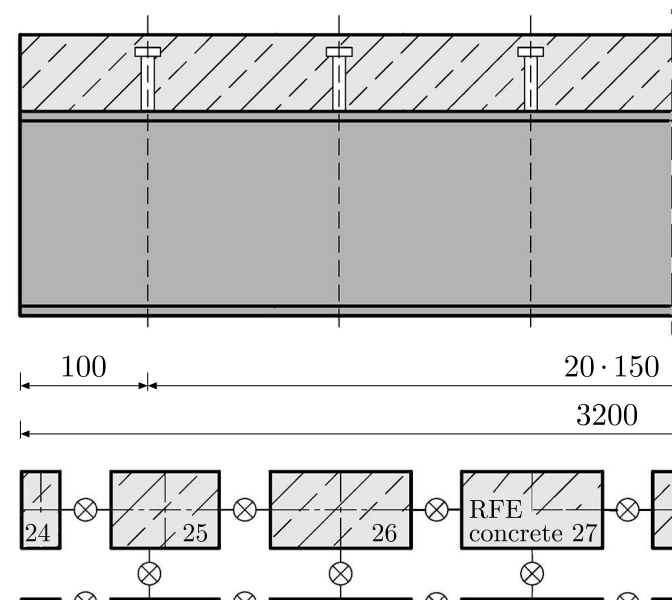

$20 \cdot 150$

3200

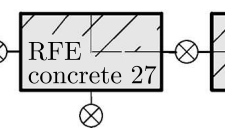

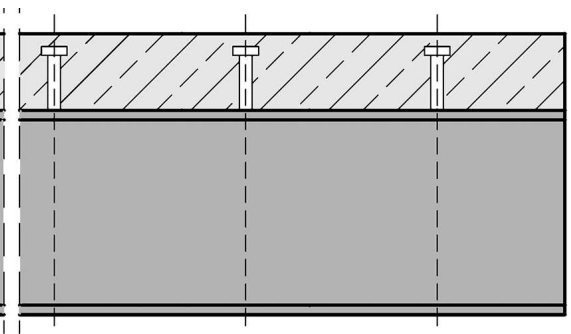

100
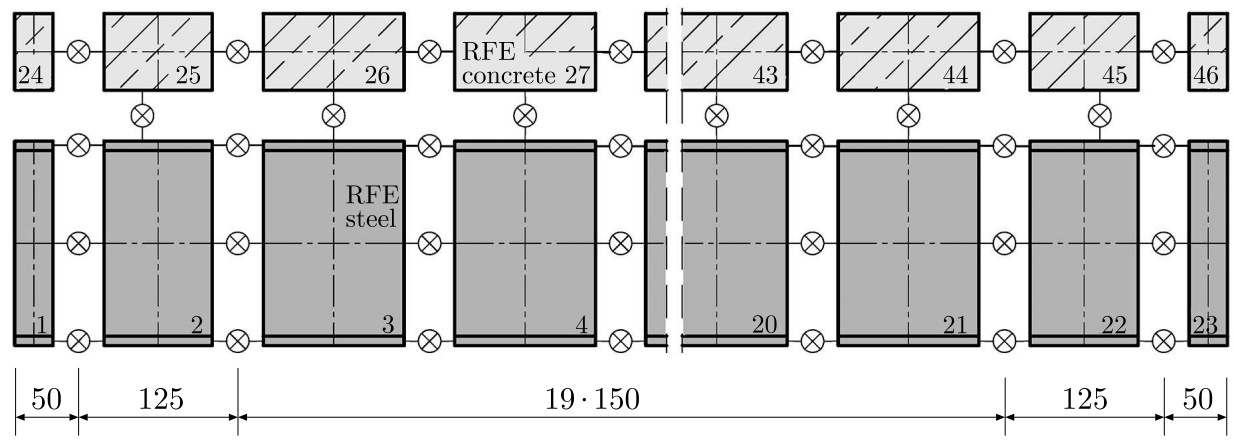

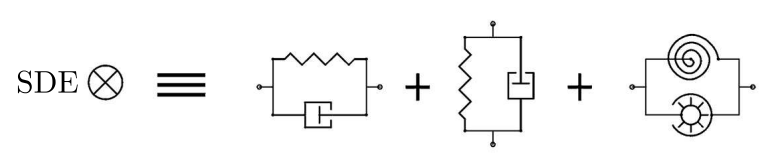

Fig. 5. RFE model of the composite beam: (a) primary division, (b) secondary division

The second identification criterion is defined as the complete fit of the fundamental frequency of axial vibration determined numerically and experimentally (it is due to strong correlation of this frequency with Young's modulus of the concrete slab $E_{c}$ ). Identification process has been conducted with a MATLAB optimization toolbox, using fmincon function which finds a minimum of a constrained nonlinear multivariable function. The function can be used to find a minimum with four different algorithms. Active-set and Interior-point were tested during the analysis. Finally, the second algorithm was selected. The algorithm required determination of the Hessian matrix, a matrix of second-order derivatives. The Hessian was determined using BFGS, a variable metric method. The obtained fit of frequencies and the results of stiffness parameter identification are presented in Table 2.

Table 2. Identification results of stiffness properties of the beam

\begin{tabular}{|c||c|c|c|c|c||c|}
\hline$i \rightarrow$ & $1_{\text {flex }}$ & $2_{\text {flex }}$ & $3_{\text {flex }}$ & $4_{\text {flex }}$ & $5_{\text {flex }}$ & $1_{a x}$ \\
\hline \hline$f_{i, \exp }[\mathrm{Hz}]$ & 74.68 & 172.72 & 273.01 & 373.40 & 472.03 & 585.94 \\
\hline$f_{i, \text { num }}[\mathrm{Hz}]$ & 74.93 & 170.91 & 275.55 & 375.06 & 469,05 & 585.94 \\
\hline$\Delta_{i}$ & $0.34 \%$ & $-1.05 \%$ & $0.93 \%$ & $0.44 \%$ & $-0.63 \%$ & $0.00 \%$ \\
\hline \hline$E_{c}\left[\mathrm{~N} / \mathrm{m}^{2}\right]$ & \multicolumn{5}{|c|}{$2.89 \cdot 10^{10}$} \\
\hline$K_{h}[\mathrm{~N} / \mathrm{m}]$ & \multicolumn{6}{|c|}{$2.19 \cdot 10^{8}$} \\
\hline$K_{v}[\mathrm{~N} / \mathrm{m}]$ & \multicolumn{1}{|c|}{$1.44 \cdot 10^{8}$} \\
\hline
\end{tabular}

At the second identification stage, the values of parameters defining damping properties, loss factors for concrete $Q_{c}^{-1}$ and connection $Q_{c o n}^{-1}$, have been identified. According to Rao (2004), the loss factor for steel is $Q_{s}^{-1} \in\left\langle 2 \cdot 10^{-4}, 6 \cdot 10^{-4}\right\rangle$. Finally, the loss factor for steel was predefined to be equal $Q_{s}^{-1}=4 \cdot 10^{-4}$. The identification process was based on fitting the amplitudes 
of the frequency response function (FRFs) obtained using RFE model with those obtained during the experiment. For FRFs determined in the vertical direction (axis $Y$, impulse excitation at point $53:-Y$ ), the frequency range from $50 \mathrm{~Hz}$ do $350 \mathrm{~Hz}$ was fitted. The range includes frequencies of the first three modes of flexural vibration. For FRFs determined in the horizontal direction (axis $X$, impulse excitation at point $54:+X$ ), the frequency range including the fundamental longitudinal vibration was considered. The following loss factors were determined in the identification: $Q_{c}^{-1}=0.0100$ and $Q_{c o n}^{-1}=0.0269$. Figure 6 shows a comparison of illustrative FRFs obtained experimentally with those calculated with the RFE model. The numbers of points from a grid of measurement points used during the experiment and their corresponding rigid finite elements numbers from the numerical model are given in Fig. 6. Location of RFE No. 7 and RFE No. 17 corresponds exactly to the location of point No. 16 and point No. 40 which was placed on the bottom flange of the I-section during experiment (see Fig. 2).
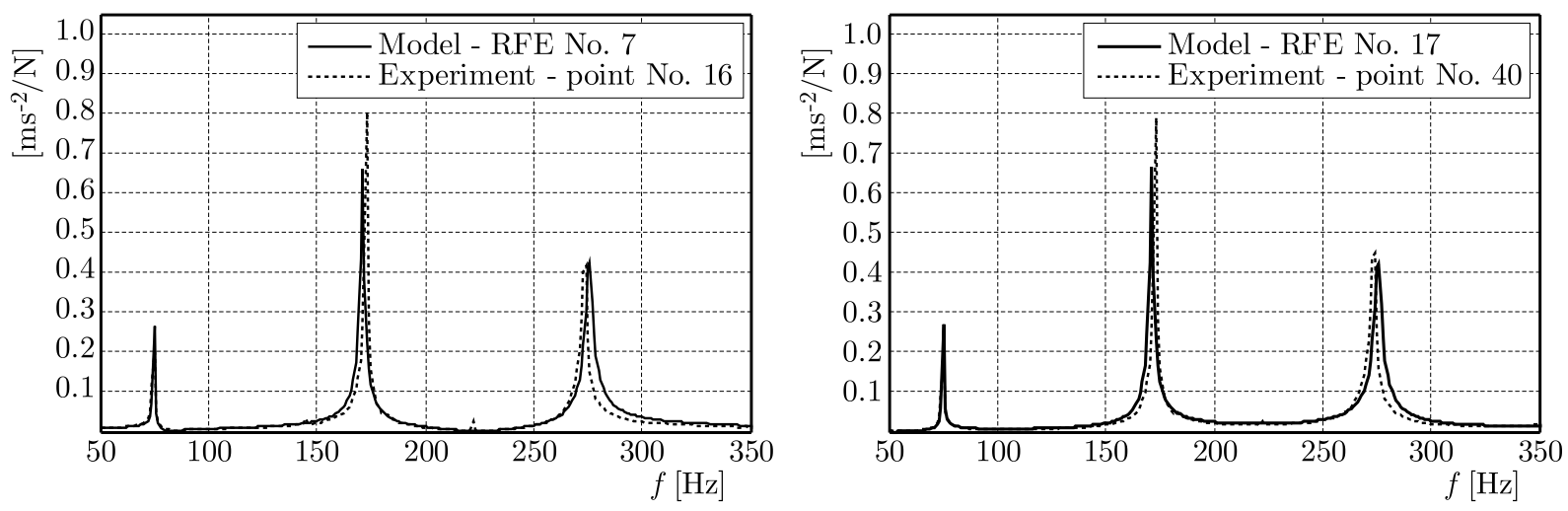

Fig. 6. A comparison of FRFs ( $Y$ direction) obtained in the experimental research and those simulated with the RFE model. The excitation force applied at point $53:-Y$

The comparison of the experimental and numerical mode shapes of vibration has been determined using the Modal Assurance Criterion - MAC (Allemang and Brown, 1982)

$$
M A C=\frac{\left|\mathbf{Q}_{\text {num }}^{\mathrm{T}} \mathbf{Q}_{\text {exp }}\right|^{2}}{\left(\mathbf{Q}_{\text {num }}^{\mathrm{T}} \mathbf{Q}_{\text {num }}\right)\left(\mathbf{Q}_{\text {exp }}^{\mathrm{T}} \mathbf{Q}_{\text {exp }}\right)}
$$

where the vectors $\mathbf{Q}_{\text {num }}$ and $\mathbf{Q}_{\text {exp }}$ denote respectively mode shapes determined numerically and experimentally. The obtained values of $M A C$ are presented in Table 3.

Table 3. Values of the coefficient MAC

\begin{tabular}{|c||c|c|c|c|c|}
\hline$i \rightarrow$ & $1_{\text {flex }}$ & $2_{\text {flex }}$ & $3_{\text {flex }}$ & $4_{\text {flex }}$ & $5_{\text {flex }}$ \\
\hline \hline$M A C_{i}$ & 0.97 & 0.92 & 0.88 & 0.82 & 0.72 \\
\hline
\end{tabular}

According to literature reports (Uhl, 1997), the fit of a numerical model and an experiment occurs when the $M A C$ is above 0.8 . As can be seen from Table 3 , the condition is not satisfied for the fifth mode shape. Therefore, the fifth mode shape is not included in further analysis.

Numerical simulation of damage in the connection, which included damage introduced in experiments into the real beam, has been conducted for the developed model. Damage in the connection was simulated by changing the spring properties of SDEs that modelled the connection: the stiffness coefficients of the respective SDEs were preset to equal zero $K_{h}=K_{v}=0$. 


\section{Analysis results}

The sensitivity analysis of modal parameters following damage introduced into the beam has begun with examination of changes in the fundamental modal parameters, such as natural frequency and damping ratio. Then, the energy transfer ratio (ETR) was analysed. ETR was determined globally, for the whole beam, and locally, for some parts of the beam.

\subsection{Vibration frequency and damping ratio}

The changes of natural vibrations and damping ratio after damage introduction both for the calculated and experimental data are presented in Tables 4 and 5, respectively.

Table 4. Changes of natural frequencies following beam damage

\begin{tabular}{|c|c|c|c|c|c|c|}
\hline \multirow{2}{*}{\multicolumn{2}{|c|}{$\begin{array}{c}\text { Beam state } \rightarrow \\
i \downarrow \\
\end{array}$}} & UZ0 & \multicolumn{2}{|c|}{ UZ1 } & \multicolumn{2}{|c|}{ UZ2 } \\
\hline & & $f_{i, n u m}[\mathrm{~Hz}]$ & $f_{i, \text { num }}[\mathrm{Hz}]$ & \multirow{2}{*}{ 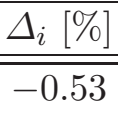 } & \multirow{2}{*}{$\begin{array}{c}f_{i, n u m}[\mathrm{~Hz}] \\
73.96\end{array}$} & \multirow{2}{*}{$\frac{\Delta_{i}[\%]}{-1.29}$} \\
\hline \multirow{4}{*}{ 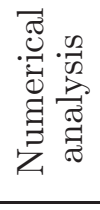 } & $1_{\text {flex }}$ & 74.93 & 74.53 & & & \\
\hline & $2_{\text {flex }}$ & 170.91 & 170.23 & -0.40 & 168.89 & -1.18 \\
\hline & $3_{\text {flex }}$ & 275.55 & 272.87 & -0.97 & 265.71 & -3.57 \\
\hline & $4_{\text {flex }}$ & 375.06 & 369.74 & -1.42 & 363.58 & -3.06 \\
\hline \multicolumn{2}{|c|}{$\downarrow \downarrow$} & $f_{i, \exp }[\mathrm{Hz}]$ & $f_{i, \exp }[\mathrm{Hz}]$ & $\Delta_{i}[\%]$ & $f_{i, \exp }[\mathrm{Hz}]$ & $\Delta_{i}[\%]$ \\
\hline \multirow{4}{*}{ 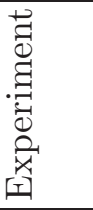 } & $1_{\text {flex }}$ & 74.68 & 73.97 & -0.95 & 73.29 & -1.86 \\
\hline & $2_{\text {flex }}$ & 172.72 & 170.22 & -1.45 & 167.63 & -2.95 \\
\hline & $3_{\text {flex }}$ & 273.01 & 267.45 & -2.04 & 259.91 & -4.80 \\
\hline & $4_{\text {flex }}$ & 373.40 & 365.50 & -2.12 & 357.81 & -4.18 \\
\hline
\end{tabular}

As can be seen in Table 4, high consistency of natural frequency changes determined experimentally and numerically has been achieved. Somewhat larger changes of the parameter, following damage introduction, were recorded in experimental measurements. In each analysed case, an increase of damage extent caused a decrease in the natural frequency, which was directly associated with a stiffness loss of the beam.

Table 5. Changes of the damping ratio following beam damage

\begin{tabular}{|c|c|c|c|c|c|c|}
\hline \multirow{2}{*}{\multicolumn{2}{|c|}{$\begin{array}{c}\text { Beam state } \rightarrow \\
i \downarrow \\
\end{array}$}} & \multirow{2}{*}{$\begin{array}{l}\mathrm{UZ0} \\
\text { num }[\%]\end{array}$} & \multicolumn{2}{|c|}{ UZ1 } & \multicolumn{2}{|c|}{ UZ2 } \\
\hline & & & \multirow{2}{*}{$\frac{\xi_{i, \text { num }}[\%]}{0.28}$} & \multirow{2}{*}{$\begin{array}{c}\Delta_{i}[\%] \\
9.62\end{array}$} & \multirow{2}{*}{$\begin{array}{c}\xi_{i, \text { num }}[\%] \\
0.33\end{array}$} & \multirow{2}{*}{$\frac{\Delta_{i}[\%]}{27.04}$} \\
\hline \multirow{4}{*}{ 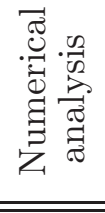 } & $1_{\text {flex }}$ & 0.26 & & & & \\
\hline & 2 flex & 0.41 & 0.42 & 4.74 & 0.51 & 26.47 \\
\hline & $3_{\text {flex }}$ & 0.51 & 0.57 & 12.98 & 0.86 & 68.67 \\
\hline & $4_{\text {flex }}$ & 0.61 & 0.68 & 11.47 & 0.78 & 27.02 \\
\hline \multicolumn{2}{|c|}{$i \downarrow$} & $\xi_{i, \exp }[\%]$ & $\xi_{i, \exp }[\%]$ & $\Delta_{i}[\%]$ & $\xi_{i, \exp }[\%]$ & $\Delta_{i}[\%]$ \\
\hline \multirow{4}{*}{ 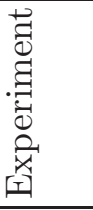 } & $1_{\text {flex }}$ & 0.15 & 0.16 & 4.79 & 0.16 & 4.99 \\
\hline & $2_{\text {flex }}$ & 0.30 & 0.28 & -5.56 & 0.29 & -1.86 \\
\hline & $3_{\text {flex }}$ & 0.41 & 0.44 & 9.28 & 0.44 & 8.27 \\
\hline & $4_{\text {flex }}$ & 0.39 & 0.44 & 12.86 & 0.45 & 15.66 \\
\hline
\end{tabular}

Changes in the damping ratio determined experimentally and numerically do not show the level of similarity as in the frequency. The ratio is more sensitive than natural frequencies to damage introduction, which is particularly true for numerical simulation results. There is a tendency for the damping ratio to increase as damage extent increases. 


\subsection{Energy transfer ratio ETR}

The sensitivity analysis of the energy transfer ratio ETR for damage introduced into the steel-concrete composite beam has been conducted in two stages. First, the results of numerical simulations of damage produced with the rigid finite element model were analysed. Then, the sensitivity analysis of ETR based on experimental results was conducted.

The equilibrium of a vibrating system with $\mathrm{n}$ degrees of freedom, including the effect of damping, can be given by a system of differential equations

$$
\mathbf{M} \ddot{\mathbf{X}}+\mathbf{C} \dot{\mathbf{X}}+\mathbf{K X}=\mathbf{F}
$$

where: $\mathbf{M}, \mathbf{C}, \mathbf{K}$ - are mass, damping and stiffness matrices, $\ddot{\mathbf{X}}, \dot{\mathbf{X}}, \mathbf{X}$ - vectors of acceleration, velocity and displacement, $\mathbf{F}$ - the external force vector.

When considering free damped vibrations, the above equation can be written as

$$
\ddot{\mathbf{Y}}+\overline{\mathbf{C}} \dot{\mathbf{Y}}+\overline{\mathbf{K}} \mathbf{Y}=\mathbf{0}
$$

where: $\mathbf{Y}=\mathbf{M}^{0.5} \mathbf{X}, \overline{\mathbf{C}}=\mathbf{M}^{-0.5} \mathbf{C M}^{-0.5}, \overline{\mathbf{K}}=\mathbf{M}^{-0.5} \mathbf{K M}^{-0.5}$.

For the system defined with Eq. (4.2), there is a set of modal parameters, i.e. natural frequencies $\omega_{i}$, modal damping ratios $\xi_{i}$ and the mode shapes $\overline{\mathbf{P}}_{i}$, where $i=1, \ldots, n$. For the generalized stiffness matrix $\overline{\mathbf{K}}$, there are eigenvectors $\overline{\mathbf{Q}}_{i}$, for which in proportionally damped systems it is true that $\overline{\mathbf{Q}}_{i}=\overline{\mathbf{P}}_{i}$. In non-proportionally damped systems, for which $\overline{\mathbf{Q}}_{i} \neq \overline{\mathbf{P}}_{i}$, it is true that (Liang and Lee, 1991)

$$
\zeta_{i}=\operatorname{Im}\left(\frac{1}{2 \omega_{i}} \frac{\overline{\mathbf{Q}}_{i}^{\mathrm{T}} \overline{\mathbf{C P}}_{i}}{\overline{\mathbf{Q}}_{i}^{\mathrm{T}} \overline{\mathbf{P}}_{i}}\right)
$$

where $\zeta_{i}$ denotes the energy transfer ratio ETR. The component $\left(\overline{\mathbf{Q}}_{i}^{\mathrm{T}} \overline{\mathbf{C P}}_{i}\right) /\left(\overline{\mathbf{Q}}_{i}^{\mathrm{T}} \overline{\mathbf{P}}_{i}\right)$ is defined as the generalized Rayleigh quotient.

A more comprehensive discussion of ETR can be found in reports by Liang and Lee (1991) and by Wang and Zong (2002).

\subsubsection{Numerical analysis}

Table 6 presents changes in the global ETR determined in numerical simulation of the beam

\begin{tabular}{|c|c|c|c|c|c|c|}
\hline \multicolumn{2}{|c|}{ Beam state $\rightarrow$} & UZ0 & \multicolumn{2}{|l|}{ UZ1 } & \multicolumn{2}{|l|}{ UZ2 } \\
\hline \multirow{5}{*}{ 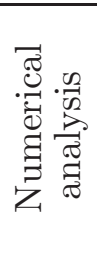 } & $i \downarrow$ & $\zeta_{i, \text { num }} \cdot 10^{2}[\%]$ & $\zeta_{i, \text { num }} \cdot 10^{2}[\%]$ & $\Delta_{i}[\%]$ & $\zeta_{i, \text { num }} \cdot 10^{2}[\%]$ & $\Delta_{i}[\%]$ \\
\hline & 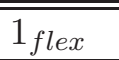 & 2.9 & 3.7 & 27 & "5.5 & 89 \\
\hline & $2_{\text {flex }}$ & 4.3 & 5.0 & 16 & 12.3 & 187 \\
\hline & 3 flex & 4.9 & 7.6 & 56 & 28.9 & 495 \\
\hline & $4_{\text {flex }}$ & 5.4 & 7.4 & 38 & 12.5 & 132 \\
\hline
\end{tabular}
damage.

Table 6. Changes of global ETR following beam damage

The analysis of the data demonstrates that the value of ETR increases with an increase in the degree of damage in the connection of the beam. ETR can be said to be substantially more sensitive to this type of damage than both the natural frequency and damping ratio. The largest change of ETR occurred in the third mode shape, for UZ2 damage, when it amounted to $495 \%$.

As mentioned above, the local ETR was determined for parts of the beam. It is to be emphasised that the division into parts was conducted individually for each mode shape, so that 
each analysed part covered the area of a substantial curvature while at the same time avoiding nodes of the mode shape. The analysis started from the second mode shape.

Figure 7 shows changes of the locally determined ETR following damage introduction. The figure also presents the calculated mode shapes for the undamaged beam - the horizontal axis shows the localisation of damaged stud connectors.

(a)
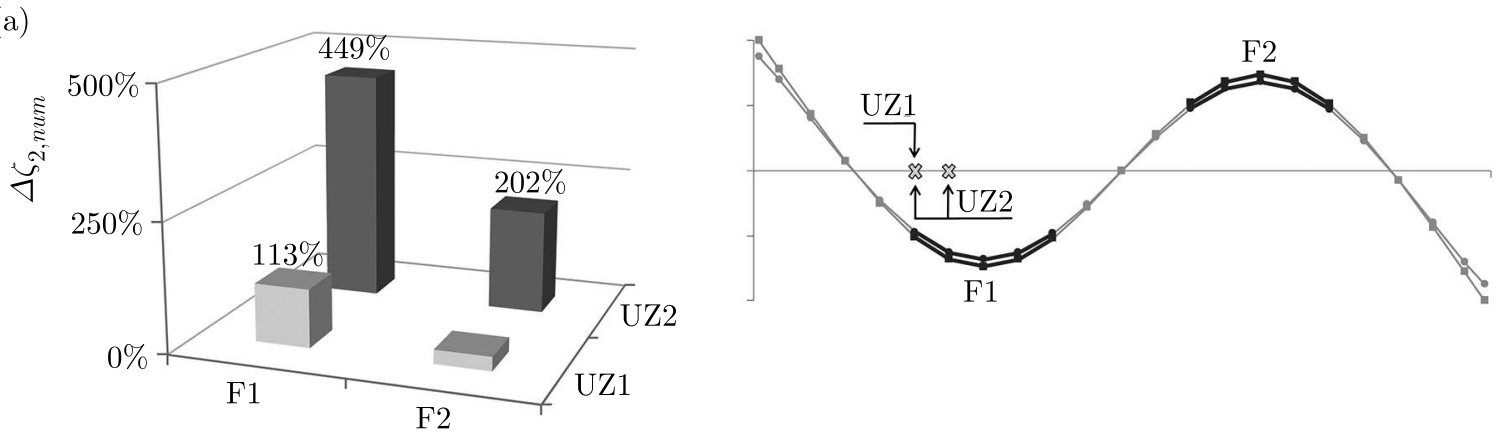

(b)
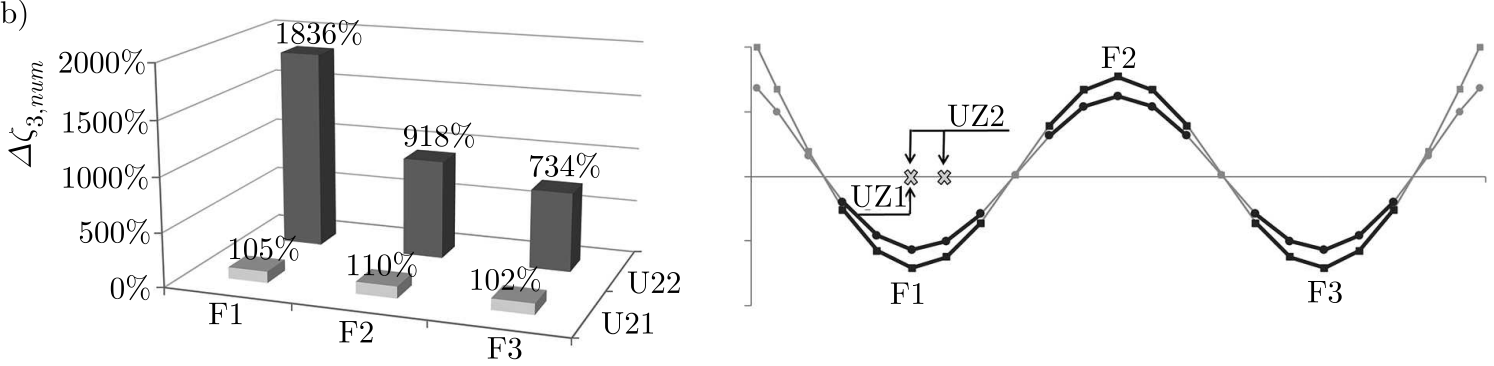

(c)
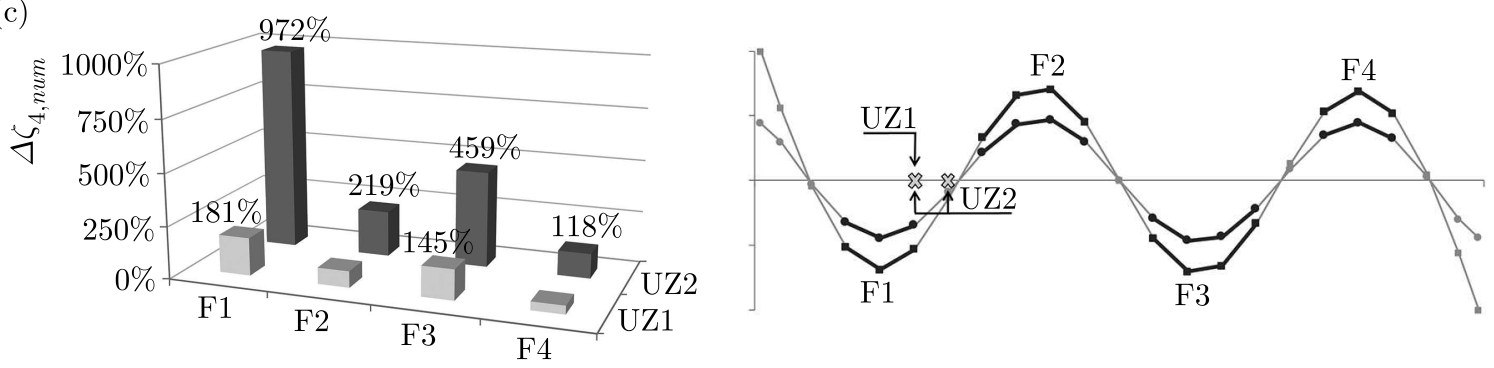

Fig. 7. Changes of local ETR $\zeta_{i, n u m}$ with mode shapes and damage area: (a) 2nd mode shape, (b) 3rd mode shape, (c) 4th mode shape

The changes of the locally determined ETR distinctly show the area of damage. The minimum sensitivity was observed for UZ1 damage, where the maximum change was $181 \%$. Much larger changes occurred for UZ2 damage, with the order of magnitude ranging from several hundreds to even several thousands percent. The highest sensitivity was observed for the third mode shape when ETR change was $1836 \%$.

\subsubsection{Experimental analysis}

To determine ETR based on experimental data, it is necessary to know the damping matrix $\overline{\mathbf{C}}$. The matrices determined for the RFE model for successive states of the beam, UZ0, UZ1 and UZ2, were used in the analysis.

Table 7 shows changes of global ETR determined with the experimental data. The results include changes that occurred for the second, third and fourth mode shape, i.e. those which were going to be analysed in damage localisation.

The ETR changes determined with the experimental data occurred in the range of $13 \%$ $-268 \%$. Compared to numerical analysis results, the changes are smaller. However, it is to be 
Table 7. Changes of the global ETR following beam damage

\begin{tabular}{|c|c|c|c|c|c|c|}
\hline \multicolumn{2}{|c|}{ Beam state $\rightarrow$} & UZ0 & \multicolumn{2}{|l|}{ UZ1 } & \multicolumn{2}{|l|}{ UZ2 } \\
\hline $\bar{Z}$ & $i \downarrow$ & $\zeta_{i, \text { num }} \cdot 10^{2}[\%]$ & $\zeta_{i, \text { num }} \cdot 10^{2}[\%]$ & $\Delta_{i}[\%]$ & $\zeta_{i, \text { num }} \cdot 10^{2}[\%]$ & $\Delta_{i}[\%]$ \\
\hline 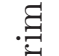 & $22_{\text {flex }}$ & 20.5 & 50.8 & 147 & 75.4 & 268 \\
\hline ब. & $3_{\text {flex }}$ & 26.8 & 7.2 & 73 & 68.6 & 156 \\
\hline 夙 & $4_{\text {flex }}$ & 30.6 & 8.0 & 74 & 34.5 & 13 \\
\hline
\end{tabular}

emphasised that the numerical analysis was not affected by distortions which did take place during real measurements. The presence of uncontrolled distortions and measurement noise may affect the results. However, despite this fact, changes of ETR, compared to frequency and damping ratio changes, are much larger. It demonstrates that ETR is more sensitive to the damage introduced into the beam.

Changes of local ETR following the connection damage are presented in a graphical form in Fig. 8. Figure 8 also shows experimentally the determined mode shapes for the undamaged beam - the horizontal axis shows the localisation of damaged stud connectors.

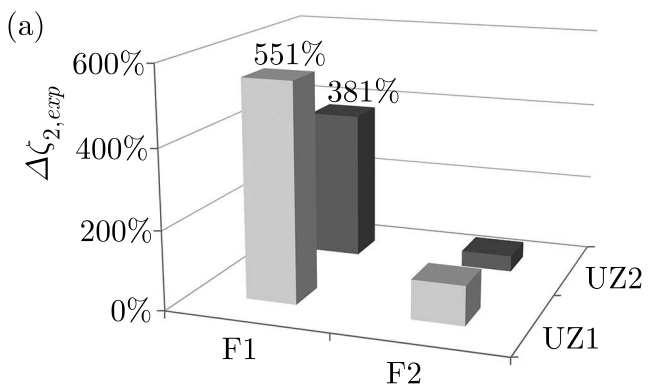

(b)

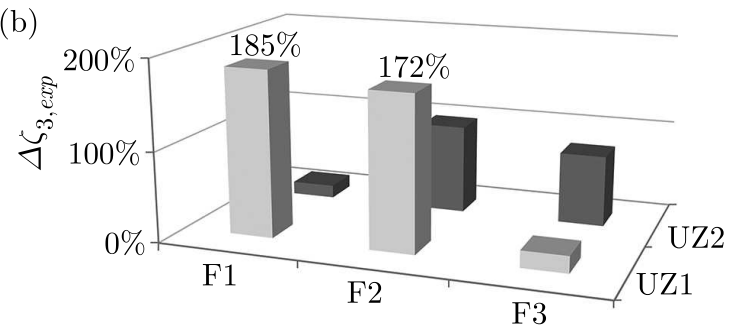

(c)

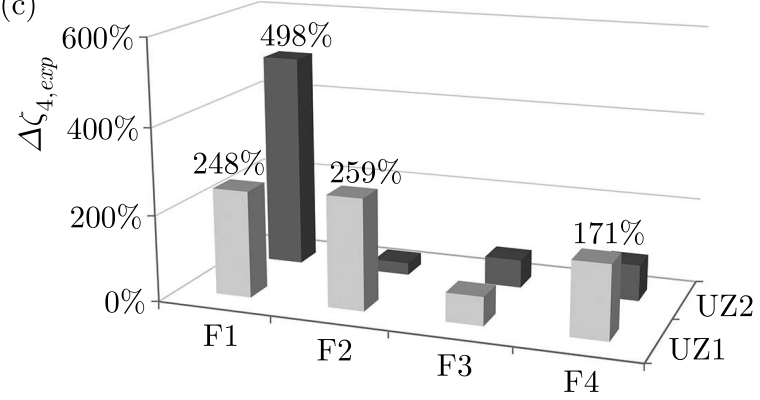

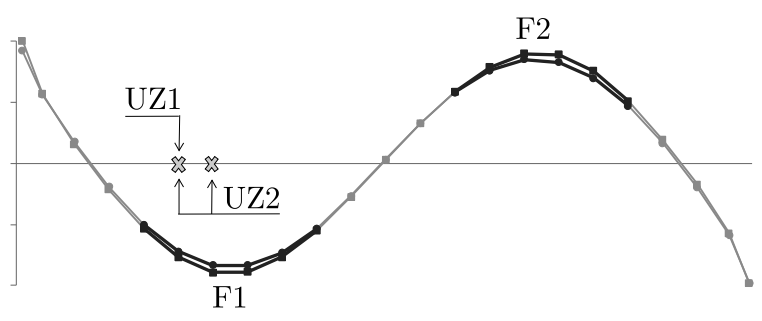
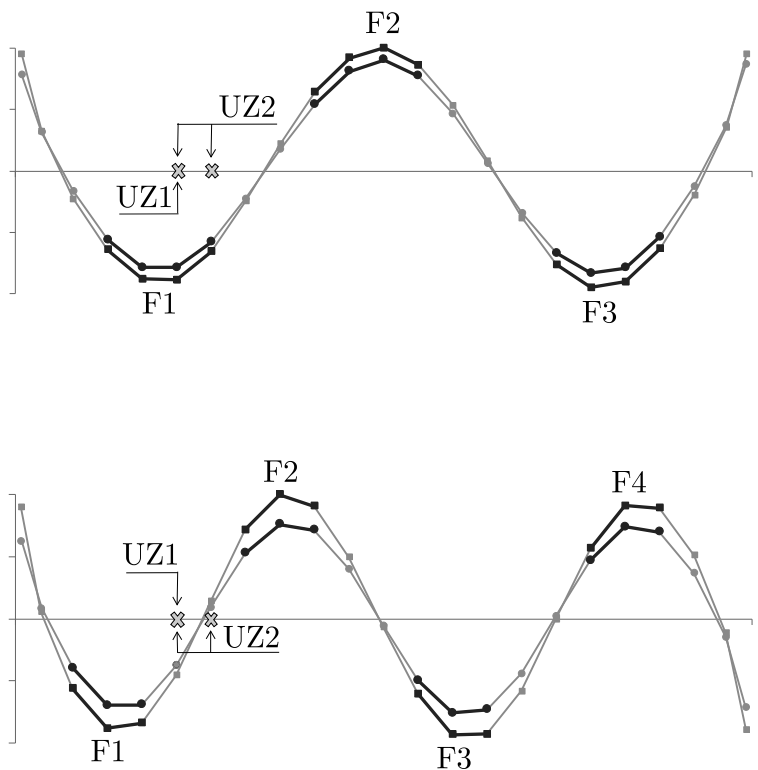

Fig. 8. Changes of local ETR $\zeta_{i, \exp }$ with mode shapes and damaged areas: (a) 2nd mode shape,

(b) 3rd mode shape, (c) 4th mode shape

The analysis of graphs presented in Fig. 8 can identify locations where damage occurred. Very good results were obtained for the second and fourth mode shapes. A comparison of Figs. 8 and 7 reveals that changes determined with the experimental data are smaller than those obtained in 
numerical simulation. As mentioned above, this is due to the influence of external factors and measurement noise.

More comprehensive data on the experimental research, the model and the numerical analysis can be found elsewhere (Jarosińska, 2014).

\section{Conclusions}

The paper presents results of sensitivity analysis conducted for natural frequencies, damping ratio and energy transfer ratio following damage introduced into the connection of a steelconcrete composite beam. Both numerical analysis results and experimental research confirmed that ETR is more sensitive to the beam damage than the vibration frequency and damping ratio. Interestingly, it is possible to effectively localise the damage introduced into the beam, based on the analysis of changes of the locally determined ETR. It must be stressed, however, that the determination of ETR requires experimental measurements to be conducted with high precision since the method is based on changes in composite mode shapes.

Diagnostics of structures is a multistage process. Firstly, the damage must be detected using modal parameters determined globally for the whole structure: vibration frequency, modal damping coefficient, global ETR, etc. Secondly, the detected damage is localised using locally determined parameters, e.g. PMAC (Heylen and Janter, 1990), CDF (Wahab and de Roeck, 1999) or local ETR which has been used in the paper. Effectiveness of any method may be dependent on external factors and measurement apparatus. The best way to detect and precisely localise the damage is to use several methods at the same time. Evaluation of changes in modal parameters, including global and local ETR, when accompanied by other methods, may be a successful tool for detecting and localising damage in steel-concrete composite structures.

The problem of damage detection and localisation in composite beams is going to be continued in further research. Future investigations will be extended to include other types of damage and localisation techniques.

\section{References}

1. Allemang R.J., Brown D.L., 1982, Correlation coefficient for modal vector analysis, Proceedings of the 1st International Modal Analysis Conference, Orlando, Florida, 110-116

2. Dilena M., Morassi A., 2003a, A damage analysis of steel-concrete composite beams via dynamic methods: Part I. Experimental results, Journal of Vibration and Control, 9, 507-527

3. Dilena M., Morassi A., 2003b, A damage analysis of steel-concrete composite beams via dynamic methods: Part II. Analytical models and damage detection, Journal of Vibration and Control, 9, $529-565$

4. Dilena M., Morassi A., 2004, Experimental modal analysis of steel concrete composite beams with partially damaged connection, Journal of Vibration and Control, 10, 897-913

5. Dilena M., Morassi A., 2009, Vibrations of steel-concrete composite beams with partially degraded connection and application to damage detection, Journal of Sound and Vibration, 320, 1/2, $101-124$

6. Heylen W., Janter T., 1990, Extensions of the modal assurance criterion, Journal of Vibration and Acoustics, 112, 468-472

7. JarosińsKa M., 2014, Detection of steel-concrete compound beams through modal analysis (in Polish), Doctoral disertation, Zachodniopomorski Uniwersytet Technologiczny w Szczecinie, Wydział Budownictwa i Architektury, Szczecin 
8. Kong F., Liang Z., LeE G.C., 1996, Bridge damage identification through ambient vibration signature, Proceedings of the 14th International Modal Analysis Conference, Dearborn, Michigan, 717-724

9. Kruszewski J., Gawroński W., Wittbrodt E., Najbar F., Grabowski S., 1975, Rigid Finite Element Method (in Polish), Arkady, Warszawa

10. Kruszewski J., Sawiak S., Wittbrodt E., 1999, CAD CAM: Rigid Finite Element Method in Structural Dynamics (in Polish), Wydawnictwa Naukowo-Techniczne, Warszawa

11. Lee G.C., Liang Z., 1999, Development of a bridge monitoring system, Proceedings of the 2nd international Workshop on Structural Health Monitoring, Standford University, California, 349-358

12. Li J., HaO H., Xia Y., Zhu H., 2014, Damage detection of shear connectors in bridge structures with transmissibility in frequency domain, International Journal of Structural Stability and Dynamics, 14, 2

13. Li J., Haо H., Zhu H., 2014, Dynamic assessment of shear connectors in composite bridges with ambient vibration measurements, Advances in Structural Engineering, 17, 5, 617-638

14. Liang Z., LeE G.C., 1991, Damping of structures: Part 1 - Theory of complex damping, National Center for Earthquake Engineering Research, Technical Report NCEER-91-0004, State University of New York at Buffalo, New York

15. Liang Z., Huang T.J., Lee G.C., 1997, A study on damage dynamics by using the modal energy transfer, Proceedings of the 15th International Modal Analysis Conference, Orlando, Florida, 1339-1345

16. Liu K., De Roeck G., 2009, Damage detection of shear connectors in composite bridges, Structural Health Monitoring, 8, 5, 345-356

17. RaO S.S., 2004, Mechanical Vibrations, Fourth Edition, Pearsons Education International, New Jersey

18. UHL T., 1997, CAD CAM: Computer Aided identification of Models of Mechanical Structures (in Polish), Wydawnictwa Naukowo-Techniczne, Warszawa

19. Waнав M.A., De Roeck G., 1999, Damage detection in bridges using modal curvatures: Application to a real damage scenario, Journal of Sound and Vibration, 226, 2, 217-235

20. WANG T.L., Zong Z., 2002, Improvement of evaluation method for existing highway bridges, Technical Report FL/DOT/RMC/6672-818, Florida Department of Transportation, USA

21. WANG T.L., Zong Z.H., 2003, Structural damage identification by using energy transfer ratio, Proceedings of the 21st International Modal Analysis Conference: A Conference on Structural Dynamics, Kissimmee, Florida

22. Wittbrodt E., Adamiec-Wójcik I., Wojciech S., 2006, Dynamics of Flexible Multibody Systems. Rigid Finite Element Method, Springer-Verlag, Berlin, Heidelberg, New York

23. Wróblewski T., Jarosińska M., Berczyński S., 2011, Application of ETR for diagnosis of damage in steel-concrete composite beams, Journal of Theoretical and Applied Mechanics, 49, 1, $51-70$

24. Wróblewski T., Jarosińska M., Berczyński S., 2013, Damage location in steel-concrete composite beams using Energy Transfer Ratio (ETR), Journal of Theoretical and Applied Mechanics, 51, 1, 91-103 